\title{
Myxoid/round cell liposarcoma
}

INSERM

\section{Source}

INSERM. (1999). Orphanet: an online rare disease and orphan drug data base.

Myxoid/round cell liposarcoma. ORPHA:99967

Myxoid/round cell liposarcoma (MRCLS) is a type of liposarcoma (LS; see this term)

mostly located in the limbs, with a variable behavior depending on the histological subtype. Both myxoid and round cell are distinct histological subtypes of LS. 